\title{
Organizational Commitment Can Be Predicted? Comparative and Descriptive Analysis
}

\author{
Dr. Reka Janos \\ Dr. Kinga Szabo
}

\section{Abstract}

Organizational commitment has been in researchers' focus for a long period and it is very important for organizational practice. The aim of this study is to investigate the role of situational and personal factors in organizational commitment. 531 job applicants completed the Blau and a demographic questionnaire from different Romanian and Hungarian organizations. The study sample included employees and leaders as well. Differentiated effect and relations, professional and organizational commitment, job involvement and work value were investigated. Results indicate significant differences in level of organizational and occupational commitment based on participants' educational level. Moreover, the status in organization had significant effect on all four commitment dimensions. The cultural effect was not demonstrated. Findings can be useful in practice to keep up proper labor.

Keywords: occupational and organizational commitment, job involvement, work value, demographic factors, employees, leaders

\section{Introduction}

Organizational commitment plays an important role in achieving organizational goals. This is a complex construct containing emotional, behavioral and cultural aspects.

Commitment is a psychological state that characterizes the relationship of the worker with the organization. Within the commitment, we can distinguish between emotional and behavioral attitudes. At the emotional attitude side, focus is on the relationship between the individual and the organization, while the behavioral side means action intent or activity (Meyer et al. (2002). Commitment to the organization may be strong or weak. Strong level of it is the most advantageous thing, as this means that a worker is happy with his work, loves it, and does not intend to quit. Workers who have a high organizational affectionate commitment are emotionally attached to the organization so they have a desire to make a significant contribution to reach the organization's goals. Such individuals have no turnover intentions, work harder, and their overall performance is much better than their low-committed colleagues'. Low level of engagement is against organizational goals (Fornes et al, 2008).

Occupational and organizational commitment are two distinct constructs, but interrelated. Both are positively related to organizational retention (Mathieu and Zajac 1990). An increasing number of studies are concerned on correlates of occupational and organizational commitment, personal factors (e.g. age, gender, and study level), situational factors (e.g. organizational size, ownership) and job related factors. (Eisenberger, Huntington, Hutchison and Sowa, 1986, Aven, Parker, McEvoy, 1993, Cohen, 1993, Lee et al., 2000, Riketta, 2002,).

Among personal factors age is positively related to occupational commitment, but it has no significant effect on organizational commitment. This finding was outlined in two meta-analyses as well (Mathieu and Zajac 1990, Lee et al. 2000). According to Mathieu and Zajac (1990), age is poorly associated with emotional commitment. Results are contradictory for continuous commitment.

Many studies investigated gender differences e.g. the study of Major et al. (2012), where women reported lower occupational commitment than men.

Another factor which can contribute to commitment is education level. Graduation negatively correlates with commitment. If an individual feels that his/her skills and qualifications are not recompensed by the organization, they will not be committed to their organization (e.g. González et al., 2016)

McKinnon et al. (2003) show, that workplace culture also plays an important role in engagement. They found that humancentered leadership has a direct consequence on the commitment of the staff. Based on the theory of situational leadership, 
different management style is desirable under different conditions, in this context we can say that there is no leadership style that has a clear consequence on commitment. For fast-running organizational development strategies, it is desirable to have autocratic style; in other cases, it may be more successful to enhance engagement by driving Laissez-faire, for example in sectors such as education. Here, this leadership style provides free development of high-skilled workers in their work.

An examination about influential factors of organizational engagement dealt with the size, structure and centralization of the organization. It has a negative impact on engagement where job roles and tasks are not well defined (Jaros et al., 1993). The other direction of the research investigated the significance and role of leadership style for engagement. The leadership initiative, open communication and attention to colleagues, positively correlate with engagement. In addition, they were looking at the fairness of the orderly justice, how fair their decision-making process was. DeConinck and Stilwell (2004). It was assumed that the degree of organizational commitment was a direct predictor of the intention to change jobs. It was demonstrated that the perception of organizational justice, roles in the workplace - role recognition, role conflicts, satisfaction with earnings and satisfaction with control are directly related to organizational commitment.

Kuvaas (2003) investigated the effect of ownership on performance in the case of profit-oriented companies. He found that change in ownership patterns could be a motivating force for better performance. In the review of the author, the employees received a full-time benefit-based bonus for a year after the company's shares. This kind of financial participation has led to more favorable employee attitudes and behaviors without causing a lot of problems. The fact of ownership thus strengthens the commitment of the employees to the organization by creating a common interest between the worker and the owner.

In this study, the aim is to analyse how personal (age, gender, education level), organizational (organization size) and job (status) characteristics contribute for commitment.

\section{Methods}

\section{Participants}

A total of $\mathrm{N}=531$ participants were recruited for this study, mainly from two European countries, $\mathrm{N}=106$ from Romania, $\mathrm{N}=$ 420 Hungary and $\mathrm{N}=5$ mentioned other countries. Ages ranged from 20 to 67 with a mean age of 39.03 years $(\mathrm{SD}=10.77)$ on the whole sample. Distribution by gender was not equal, our sample included 325 females $(61.20 \%)$ and 206 males $(38.80 \%)$. The other main descriptive statistics of the participants are shown in Table 1.

Instruments

Demographic questionnaire was completed covering different socio-demographical elements and job related data: age, gender, education level, country, status and organization size. In order to assess participants' commitment level the Blau (1985) questionnaire was used. In addition to the organizational commitment (OC) this instrument measures three other related factors: occupational commitment $(\mathrm{OcC})$, work value (WV) and job involvement (JI). Response options ranged from 1 (strongly disagree) to 6 (strongly agree).

\section{Procedure}

The participants were asked to complete the two questionnaires mentioned in instruments section. Data in this study were collected individually and for analysis IBM SPSS Statistics (20.0) was applied. Descriptive statistics, regression analysis and Anova were used for testing our goals. Significance level was set at $p \leq .05$.

Table 1 Descriptive statistics of the participants

\begin{tabular}{llll}
\hline Demographic Variable & Category & $\mathrm{N}$ & $\%$ \\
\hline Status & Employee & 437 & 82.30 \\
& Middle manager & 63 & 11.90 \\
& Top leader & 31 & 5.80 \\
Education level & 8 grades or less & 23 & 4.30 \\
& Baccalaureate & 165 & 31.10 \\
& College or university & 223 & 42.00 \\
& Master degree & 91 & 17.10 \\
& PhD & 29 & 5.50 \\
Organization size & small & 130 & 24.50 \\
& Medium & 264 & 49.70 \\
& Large & 137 & 25.80 \\
\hline
\end{tabular}

\section{Results}




\section{Personal characteristics, organizational and occupational commitment}

Based on previous research, firstly the relation between two types of commitment using Pearson product-moment correlation was tested. The correlation coefficient $(r(529)=.50)$ shows a moderate uphill association between these two factors, which is statistically significant $(p<.001)$ result.

The first set of analyses focused on the relations between personal characteristics, occupational and organizational commitment.

We investigated the differences between Romanian and Hungarian sample in organizational commitment and the other related variables. The analysis did not reveal any significant differences between these two countries ( $p>.05)$. Therefore further analysis includes the whole sample.

A point-biserial correlation was used to measure the association between gender and occupational and organizational commitment. There was no significant connection either with occupational commitment $\left(r_{p b}(529)=.001, p=.97\right)$ or with organizational commitment $\left(\mathrm{rpb}_{\mathrm{pb}}(52)=-.007, \mathrm{p}=.87\right)$.

Differences in commitments were tested by the education level. One-way variance analysis demonstrated significant differences between groups in occupational commitment $F(4,526)=3.72 p<.01$.and also in organizational commitment $F(4,526)=2.70 p<.05$. Figure 1 illustrates commitment scores distributed by participants' education level.

In order to assess where exactly the significant differences were, post-hoc Tukey HSD analysis was run. This highlighted that participants with college or university degree $(M=47.05, S D=13.28)$ had significantly $(p<.05)$ higher occupational commitment than those with baccalaureate $(M=42.73, S D=12.98)$.

However, participants with $\mathrm{PhD}$ degree $(\mathrm{M}=19.07 \mathrm{SD}=8.66)$ had significantly $(p<.05)$ lower organizational commitment level than people with baccalaureate $(M=25.15, S D=11.41)$ and with college or university degree $(M=24.31, S D=9.37)$.

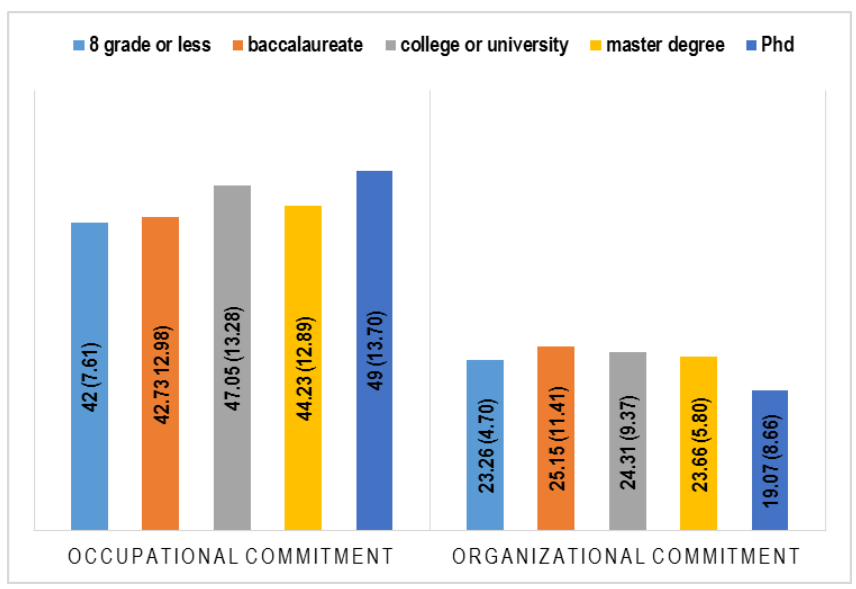

Figure 1 Occupational and organizational commitment means and standard deviations divided by education level

Last, but not least the association between age and $\mathrm{OcC}$ level and also with $\mathrm{OC}$ was inspected. Pearson product-moment correlation showed a significant $(p<.05)$ but very small positive relation $(r=10)$ with organizational commitment and no association with occupational commitment.

\section{Organizational, job characteristics and OC}

One way variance analysis was used to test the influence of status commitments. There were significant differences between the three status groups in terms of their occupational commitment $F(2,528)=10.21, p<.001$, and also in organizational commitment scores, $F(2,528)=13.72, p<.001$. Differences are shown in Figure 2. 


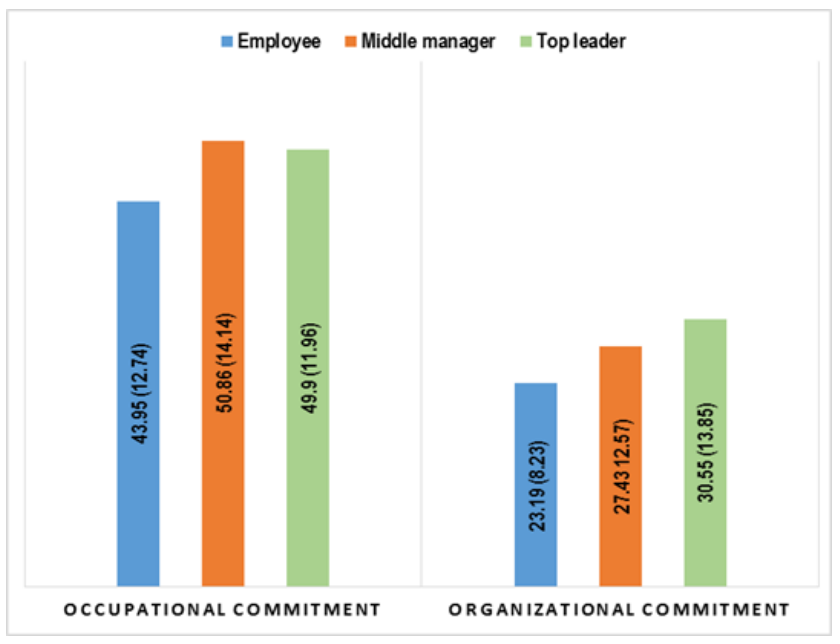

Figure 2 Occupational and organizational commitment means and standard deviations divided by status

These differences were statistically significant ( $p s<.001$ and $p s<.05)$ between employees and middle managers, and top leaders. Surprisingly, this distinctness did not come up between the two types of leaders.

In the next set of analyses, the influence of organizational factors and job related factors on organizational commitment was investigated. Summing up results from previous researches, these analyses were conducted separately by organization size (small, medium and large organization). Multiple linear regression was carried out to determine the effect of occupational commitment, work value, job involvement and status on organizational commitment. Results of these analyses are presented in Table 2-3-4.

\section{Table 2}

Regression model with OC as the criterion Variable in small organizations

\begin{tabular}{lllll}
\hline & $\begin{array}{l}\text { Unstandardiz } \\
\text { ed } \\
\text { coefficients }\end{array}$ & $\begin{array}{l}\text { Standardiz } \\
\text { ed } \\
\text { coefficients }\end{array}$ & $\mathrm{t}$ & Sig. \\
\hline Constant & -7.22 & & & \\
OcC & .17 & .14 & 2.43 & .016 \\
$\mathrm{JI}$ & .16 & .12 & 1.08 & .282 \\
Wv & .83 & .65 & 6.46 & $\mathrm{p}<.001$ \\
Status & -.10 & -.01 & -.09 & .92 \\
\hline & Unstandardiz & Standardi & $\mathrm{t}$ & Sig. \\
& ed & zed & & \\
& coefficients & coefficient & & \\
& & $\mathrm{s}$ & & \\
\hline Constant & 4.11 & & & \\
OcC & .17 & .36 & 5.56 & $\mathrm{p}<.001$ \\
Jl & .29 & .31 & 4.36 & $\mathrm{p}<.001$ \\
Wv & .09 & .09 & 1.75 & .08 \\
Status & 1.24 & .09 & 2.00 & .04 \\
\hline
\end{tabular}

\section{Table 3}

Regression model with $\mathrm{OC}$ as the criterion Variable in middle size organizations

OcC- occupational commitment, WV- work value, Jl- job involvement 
OcC- occupational commitment, WV- work value, Jl- job involvement

Adjusted $R^{2}=72.1$ per cent; $F(4,125)=84.47, p<.001$

Adjusted $R^{2}=47.9$ per cent; $F(4,259)=, p<.001$

\section{Table 4}

Regression model with OC as the criterion Variable in large size organizations

\begin{tabular}{lllll}
\hline & $\begin{array}{l}\text { Unstandardiz } \\
\text { ed } \\
\text { coefficients }\end{array}$ & $\begin{array}{l}\text { Standardiz } \\
\text { ed } \\
\text { coefficients }\end{array}$ & $\mathrm{t}$ & Sig. \\
\hline Constant & 4.02 & & & \\
OcC & .09 & .19 & 2.41 & .01 \\
$\mathrm{Jl}$ & .36 & .41 & 4.26 & $\mathrm{p}<.001$ \\
Wv & .14 & .13 & 1.59 & .11 \\
Status & 1.48 & .12 & 1.87 & .06 \\
\hline
\end{tabular}

OcC- occupational commitment, WV- work value, JI- job involvement

Adjusted $R^{2}=39.9$ per cent; $F(4,132)=23.89 .47, p<.001$

All the three models were statistically significant (ps< .001). The adjusted $R^{2}$ indicated that in small organizations 72.1 per cent, in middle organizations 47.9 per cent and in large organizations 39.9 per cent of the variance in organizational commitment score can be explained by variances in the four predictor variables. The most influential predictor was various based on organization size. Work value was the most influential predictor $(\beta=.65)$ in the model for small organizations, occupational commitment $(\beta=.36)$ for middle organizations and job involvement $(\beta=.41)$ for large size organizations. Occupational commitment was significant predictor in all three models. Therefore, work value was a significant predictor for organizational commitment only in small organizations and job involvement in middle and large size organizations.

Further analysis investigated differences in organizational commitment by status. Likewise, in previous analyses these differences were tested separately in small, middle and large size organization groups. A new variable was computed based on the status variable. This included whether a participant has an employee or a leader status. To assess these differences between employees and leaders, independent sample t-test was used. Results from these analyses are presented in Table 5.

Table 5

Differences between employees and leaders in organizational commitment separately by organization size

\begin{tabular}{lllllll}
\hline Organization type & Status & $\mathrm{N}$ & $\mathrm{M}(\mathrm{SD})$ & $\mathrm{t}(\mathrm{df})$ & $\mathrm{p}$ & $\mathrm{d}$ \\
\hline Small & Employee & 102 & $25.85(12.28)$ & $-3.23(128)$ & .002 & \multirow{2}{*}{.58} \\
organization & Leader & 28 & $35.79(20.47)$ & & & \\
Middle size & Employee & 223 & $22.79(6.07)$ & $-3.86(262)$ & $<.001$ & .69 \\
organization & Leader & 41 & $26.68(5.11)$ & & & \\
Large & Employee & 112 & $21.58(6.76)$ & $1.05(135)$ & .29 & .23 \\
organization & Leader & 25 & $23.16(6.67)$ & .29 & \\
\hline
\end{tabular}

Status has higher effect on organizational commitment among participants from middle size organizations. Interestingly, in case of large organizations status does not have any effect on this type of commitment.

\section{Discussion and Conclusion}

This study was aimed to investigate two types of commitment and how these are influenced by personal, organizational and job characteristics.

In line with previous findings (Lee et. al., 2000), occupational and organizational commitment have a positive moderate relation. These two can be overlapped, but at the same time, they can have different influential factors. 
Contrary to this meta-analytic study, age was related with organizational commitment but with occupational commitment no association was shown. However, age has only a small association with organizational commitment. This can be explained by organizational tenure and career stages. People who have spent more time in the same organization can be more committed emotionally to their organization. Further research should take into account these variables as well, controlling them, in order to establish a more clear relation between age and these two types of commitment.

Results indicated that there are differences in commitments based on educational level. These appear mostly between people with $\mathrm{PhD}$ degree, those who graduated high school and participants with university degree.

This study showed no significant differences either by genders or by nationalities. With regard to genders, this outcome contradicts the study of Major et al. (2012) that concluded difference between genders in commitment level. Women had significantly lower level of occupational commitment than men.

Due to the differences between smaller and bigger organizations, our data obtained are broadly consistent with the major trends (De Clerq, and Rius, 2007.) Interestingly, organizational commitment in small organizations was predicted significantly by work value. At the same time, this factor was not a predictor in the other two types of organizations. Job involvement was that element, which was significant predictor in middle and large size organizations as well.

Analyzing organizational and job characteristics, it was found that occupational commitment was significant predictor for organizational commitment in all types of organizations based on employee numbers.

Results indicate differences between leaders and employees in organizational commitment in two types of organizations. This highlights how important a status in small and middle organizations is, with regard to commitment. This finding can account for progress opportunities. Employees in a large organization have more chance to develop and to occupy a higher position than people from a small organization.

This study contributes to the broader literature on commitment by demonstrating that personal, organizational and job factors can have different effect on organizational and occupational commitment. From the outcome of our investigation it is possible to conclude that people with higher educational level are less committed to the organizations than those with lower educational level but they are occupationally committed. Furthermore, employees' and leaders' commitment can differ, but not in a large size organization.

\section{References}

[1] Aven, F. F., Parker, B., \& McEvoy, G. M. (1993). Gender and attitudinal commitment to organizations: A metaanalysis.Journal of Business Research, 26, 63-73.

[2] Blau, G. (1985). The measurement and prediction of career commitment. Journal of Occupational Psychology, 58, 277-288. doi: 10.1111/j.2044-8325.1985.tb00201.x

[3] Cohen, A. (1993). Age and tenure in relation to organizational commitment: A meta-analysis, Basic and Applied Social Psychology, 14, 143-159. doi: 10.1207/s15324834basp1402_2

[4] De Clerq, D, and Rius, I.,(2007). Organizational Commitment in Mexican Small and Medium-Sized Firms: The Role of Work Status, Organizational Climate, and Entrepreneurial Orientation. Journal of Small Business Management, 45, 4, 467-490, 10.1111/j.1540-627X.2007.00223.x

[5] DeConinck, J.B., Stilwell, C.D. (2004). Incorporating organizational justice, role states, pay satisfaction and supervisor satisfaction in a model of turnover intentions, Journal of Business Research, 57, 3, 225-231.

[6] Eisenberger, R., R. Huntington, S. Hutchison, and D. Sowa (1986). Perceived Organizational Support, Journal of Applied Psychology, 71, 500-507.

[7] Fornes, S. L., Rocco, T. S., \& Wollard, K. K. (2008). Workplace commitment: A conceptual model developed from integrative review of the research connections. Human Resource Development Review, 7, 3, 339-357. doi: $10.1177 / 1534484308318760$ 
[8] González, F., Sánchez, S.M. \& López-Guzmán, T. (2016) The Effect of Educational Level on Job Satisfaction and Organizational Commitment: A Case Study in Hospitality. International Journal of Hospitality \& Tourism Administration, 16, 243-259, doi:10.1080/15256480.2016.1183547

[9] Jaros, S. J. Jermier, J.M., Koehler, J.W., \& Sincich, T. (1993). Effects of continuance, affective, and moral commitment on the withdrawal process: An evaluation of eight structural equation models, Academy of Management Journal, 36, 951-995. doi: 10.2307/256642

[10] Kuvaas, B. (2003). Employee ownership and affective organizational commitment: employees' perceptions of fairness and their preference for company shares over cash. Scandinavian Journal of Management, 19, 2, 193212, doi: 10.1016/S0956-5221(01)00044-6

[11] Lee, K., Carswell, J. J., \& Allen, J. J. (2000). A meta-analytic review of occupational commitment: Relations with person- and workrelated variables. Journal of Applied Psychology, 85, 799-811. doi:10.1037/00219010.85.5.799.

[12] Major, D. A., Morganson, V.J. \& Bolen, H.M. (2013). Predictors of Occupational and Organizational Commitment in Information Technology: Exploring Gender Differences and Similarities. Journal of Business and Psychology, 28, 3, 301-31. doi:10.1007/s10869-012-9282-5

[13] Mathieu, J. E., \& Zajac, D. M. (1990). A review and meta-analysis of the antecedents, correlates and consequences of organizational commitment, Psychological Bulletin, 108, 171-194. doi:10.1037/00332909.108.2.171.

[14] McKinnon, J. L., Harrison, G. L., Chow, C. W., \& Wu, A. (2003). Organizational culture: Association with commitment, job satisfaction, propensity to remain, and information sharing in Taiwan. International Journal of Business Studies, 11, 1, 25-44.

[15] Meyer, J. P. Stanley, D.J. Herscovitch, L., Topolnytsky, L. (2002). Affective, Continuance, and Normative Commitment to the Organization: A Meta-analysis of Antecedents, Correlates, and Consequences, Journal of Vocational Behavior, 61, 20-52. doi: 10.1006/jvbe.2001.1842

[16] Riketta, M. (2002). Attitudinal organizational commitment and job performance: A meta-analysis. Journal of Organizational Behavior, 23, 257-266. doi:10.1002/job.141. 